\title{
Factors influencing visor use among players in the National Hockey League (NHL)
}

This article was published in the following Dove Press journal:

Open Access Journal of Sports Medicine

I April 2014

Number of times this article has been viewed

\author{
Robert Micieli' \\ Jonathan A Micieli² \\ 'Faculty of Science and Engineering, \\ York University, ${ }^{2}$ Department of \\ Ophthalmology and Vision Science, \\ University of Toronto, Toronto, \\ ON, Canada
}

\begin{abstract}
Eye, orbital, and facial injuries are significant risks to National Hockey League (NHL) players, and can be mitigated by the use of a partial visor - currently optional for all non-rookie players. The goal of the current study was to determine the overall use of visors among non-rookie NHL players in the 2013-2014 season and assess factors influencing their uptake. This was an observational, cross-sectional study using active NHL rosters and demographic information obtained from the official NHL website. Visor use was determined based on in-game video or images at two different time points in the 2013-2014 season. The use of visors during the 2013-2014 season was 75.2\% among non-rookie players. When rookies were included, the overall use of visors was $77.8 \%$. Compared to Canadian-born players, European players were significantly more likely to choose to wear a visor (odds ratio [OR] 3.48, 95\% confidence interval [CI] 1.96-6.17). Players in the younger age-groups, particularly those younger than 24 years (OR 5.67, 95\% CI 2.52-5.76) and those between 24 and 28 years (OR 2.18, 95\% CI 1.23-3.87), were more likely to wear a visor compared to older players. Overall, visor use continues to grow in the NHL independently of new legislation, and is more likely in younger players and those of European origin.
\end{abstract}

Keywords: ice hockey, facial protection, professional sports, eye injuries, safety

\section{Introduction}

Eye, orbital, and facial injuries are significant risks to professional hockey players, and have resulted in significant time lost from play and financial costs. The National Hockey League (NHL) is the premier professional hockey league in the world and requires players to wear protective helmets, but facial protection in the form of partial visors remained optional up to and including the 2012-2013 season. With recent injuries to high-profile players and much debate in the media, the league legislated in June 2013 that all rookie players (those that have played 26 NHL games or less) in the 2013-2014 season must wear partial visors, but continued to give all other players the option to wear them. ${ }^{1}$

There continues to be ongoing debate as to whether visors should be mandated for all players in the NHL. Proponents argue that it would protect players from deflected pucks and high sticks and save time spent on injured reserve. Opponents argue that it may restrict vision on the ice, and is ultimately a decision to be made by each player. A previous study found that a visor has no effect on visual acuity, contrast sensitivity, or color vision, but resulted in a decrease in the central $30^{\circ}$ field of vision mean-deviation index and caused a depression in the far-temporal visual field beyond $60^{\circ}{ }^{2}$
Correspondence: Jonathan A Miciel Department of Ophthalmology and Vision Science, University of Toronto, 340 College Street - Suite 400,

Toronto, ON M5T 2S8, Canada

Tel +l 4169786294

Fax +l 9053034700

Email jonathan.micieli@utoronto.ca 
Previous studies have found that visors protect NHL players from injury. A study on the NHL by Stevens et $\mathrm{al}^{3}$ found that $21 \%$ of players wore visors during the 2001-2002 season, with a protective effect on nonconcussion head injuries. A recent 10-year study using data from media reports and The Hockey News visor survey found that visor use grew from $32 \%$ to $73 \%$ from the $2002-2003$ to $2012-2013 \mathrm{NHL}$ seasons, and significantly protected players from eye and orbital injuries. ${ }^{4}$ In this study, players who chose not to wear a visor had a greater number of fights, penalty minutes, and hits than those with visors.

It remains unknown whether the recent legislation to mandate visors for new NHL players has resulted in an overall increase in visor use, and whether this has influenced nonrookie players to wear visors. To our knowledge, the factors that influence players to wear visors have not been previously reported. The goal of the current study was to determine the use of visors during the 2013-2014 season, and determine whether position played, age, or country/region of birth influences the decision to wear a visor.

\section{Materials and methods}

The study population for this cross-sectional study included NHL forwards and defensemen of all ages on the active roster of all 30 NHL teams on November 13, 2013. Goalies were excluded, since they wear a full mask during NHL games. The players on the active rosters for each team were obtained from the official league website (http://www.nhl.com) on that day. Rookie players who were recently mandated to wear visors were also obtained from the NHL website, ${ }^{5}$ and were removed from the active rosters to allow for analysis of players who had the option of using a visor. Position played, age, team, and country/region of birth were also extracted from http://www.nhl.com. Visor use was determined by direct observation from in-game video or direct observation from multiple official in-game images from October or November 2013. To ensure that NHL players did not remove or put on a visor from game to game, a random sample of 100 active players were reassessed on December 15, 2013 to see if there was any change in use of a visor. Each player and the associated demographic characteristics were extracted from the league website and analyzed statistically. Age was categorized into four major groups: those younger than 24 years of age, those between 24 and 28 years, those between 29 and 33 years, and those older than 33 years.

Statistics were performed using the SAS software suite, version 9.4 (SAS Institute, Cary, NC, USA). To determine whether age-group, position, or country/region of origin were dependent variables for visor use, Pearson's $\chi^{2}$ test was used. Each variable was tested individually for independence, and statistical significance was considered when $P<0.05$. Odds ratios (ORs) and $95 \%$ confidence intervals (CIs) were calculated using univariate logistic regression analysis for position, age-group, and country/region variables.

\section{Results}

A total of 677 NHL players were included in the study, of whom 601 were non-rookie players and had the option of wearing a protective visor. The overall use of visors during the 2013-2014 season was $77.8 \%$ for all players. When rookie players, who are required to wear visors, were eliminated from the analysis, the use of visors was $75.2 \%$. The team with the highest proportion of players using visors was the New Jersey Devils (91.7\%), and the team with the lowest proportion was the Chicago Blackhawks (63.6\%, Table 1). Median use among NHL teams was 78.2\% (standard devia-

Table I Percentage of players wearing visors in the National Hockey League (NHL) by team, as assessed in November 2013

\begin{tabular}{|c|c|c|c|}
\hline $\begin{array}{l}\text { Overall } \\
\text { rank }\end{array}$ & Team & $\begin{array}{l}\text { Overall players } \\
\text { wearing visors }\end{array}$ & $\begin{array}{l}\text { Non-rookie } \\
\text { players wearing } \\
\text { visors }\end{array}$ \\
\hline $\mathrm{I}$ & New Jersey Devils & $91.7 \%$ & $90.9 \%$ \\
\hline 2 & Edmonton Oilers & $87.0 \%$ & $84.2 \%$ \\
\hline 3 & Montreal Canadiens & $83.3 \%$ & $81.8 \%$ \\
\hline 4 & Buffalo Sabres & $81.8 \%$ & $75.0 \%$ \\
\hline 5 & Carolina Hurricanes & $81.8 \%$ & $79.0 \%$ \\
\hline 6 & Dallas Stars & $81.8 \%$ & $77.8 \%$ \\
\hline 7 & New York Islanders & $81.8 \%$ & $80.0 \%$ \\
\hline 8 & New York Rangers & $81.8 \%$ & $80.0 \%$ \\
\hline 9 & Nashville Predators & $80.9 \%$ & $76.5 \%$ \\
\hline 10 & Calgary Flames & $80.0 \%$ & $73.7 \%$ \\
\hline 11 & Los Angeles Kings & $80.0 \%$ & $80.0 \%$ \\
\hline 12 & Detroit Red Wings & $79.2 \%$ & $76.2 \%$ \\
\hline 13 & Tampa Bay Lightning & $79.2 \%$ & $72.2 \%$ \\
\hline 14 & Florida Panthers & $78.3 \%$ & $76.2 \%$ \\
\hline 15 & Pittsburgh Penguins & $78.3 \%$ & $76.2 \%$ \\
\hline 16 & San Jose Sharks & $78.3 \%$ & $76.2 \%$ \\
\hline 17 & Washington Capitals & $78.3 \%$ & $73.7 \%$ \\
\hline 18 & Phoenix Coyotes & $77.3 \%$ & $76.2 \%$ \\
\hline 19 & Colorado Avalanche & $76.2 \%$ & $75.0 \%$ \\
\hline 20 & Minnesota Wild & $76.2 \%$ & $73.7 \%$ \\
\hline 21 & Ottawa Senators & $76.2 \%$ & $73.7 \%$ \\
\hline 22 & Anaheim Ducks & $76.0 \%$ & $72.7 \%$ \\
\hline 23 & Boston Bruins & $75.0 \%$ & $73.7 \%$ \\
\hline 24 & Vancouver Canucks & $75.0 \%$ & $72.7 \%$ \\
\hline 25 & Winnipeg Jets & $75.0 \%$ & $72.7 \%$ \\
\hline 26 & Toronto Maple Leafs & $73.9 \%$ & $71.4 \%$ \\
\hline 27 & St Louis Blues & $71.4 \%$ & $71.4 \%$ \\
\hline 28 & Philadelphia Flyers & $68.1 \%$ & $65.0 \%$ \\
\hline 29 & Columbus Blue Jackets & $65.2 \%$ & $57.9 \%$ \\
\hline 30 & Chicago Blackhawks & $63.6 \%$ & $60.0 \%$ \\
\hline
\end{tabular}


tion 5.20\%). Of the random sample of 100 players reassessed 1 month later, there was no change in the status of visor use for any players.

Of the included players, $526(77.8 \%)$ were forwards and $150(22.2 \%)$ were defensemen. Of all the players with the option of wearing a visor, forward position had no association with visor use $(P=0.18)$. Of all non-rookie players, $53.0 \%$ were Canadian-born, 24.0\% were American-born, and 23.0\% were European-born. There was a statistical association between country/region of birth and visor use $(P<0.001)$. The proportion of non-rookie players wearing visors was highest among the European-born players (88.4\%), particularly Swedes (90.5\%), Russians (89.5\%) and Finns (86.7\%) compared to Canadians (68.6\%) and Americans (75.7\%). Compared to Canadian-born players, European-born athletes were significantly more likely to opt for a visor (OR 3.48, 95\% CI 1.96-6.17; Table 2).

The mean age of non-rookie players, with the option of wearing a visor, was 27.9 years (median 28.0, standard deviation 4.38). Among these players, the greatest proportion wearing visors were those players less than 24 years old $(90.6 \%)$ compared to those older than 33 years $(62.8 \%)$. There was an association between age-group and the use of visors $(P<0.001)$. Compared to players older than 33 years, players between 24 and 28 years of age (OR 2.18, 95\% CI 1.23-3.87) and players less than 24 years of age (OR 5.67, 95\% CI 2.52-12.78) were significantly more likely to choose to wear a visor (Table 3 ).

\section{Discussion}

There continues to be growth in the use of protective visors by NHL players. The use of visors has grown from $23 \%$ during the 2001-2002 season to $73 \%$ in the 2012-2013 season. ${ }^{3,4}$ We found that visor use continues to increase in the NHL independently of recent legislation mandating visor use among rookie players. Potential reasons for this increase include greater awareness regarding the risks of opting out of facial protection and continued use from the minor and

Table 2 Visor use among nonrookie players by country/region of birth

\begin{tabular}{lllll}
\hline & Visor & No visor & $\begin{array}{l}\text { Proportion } \\
\text { with visor }\end{array}$ & $\begin{array}{l}\text { Odds ratio } \\
(\mathbf{9 5 \%} \mathbf{C I})\end{array}$ \\
\hline Canada & 219 & 100 & 0.69 & Reference \\
USA & 109 & 35 & 0.76 & $1.42(0.9 \mathrm{I}-2.23)$ \\
Europe & 122 & 16 & 0.88 & $3.48(\mathrm{I} .96-6.17)$ \\
Sweden & 38 & 4 & 0.90 & $4.33(\mathrm{I} .50-12.48)$ \\
Czech Republic & 22 & 4 & 0.85 & $2.5 \mathrm{I}(0.84-7.48)$ \\
Russia & 17 & 2 & 0.89 & $3.88(0.88-17.12)$ \\
Finland & 13 & 2 & 0.87 & $2.97(0.66-13.40)$ \\
\hline
\end{tabular}

Abbreviation: $\mathrm{Cl}$, confidence interval.
Table 3 Visor use among non-rookie players by age-group

\begin{tabular}{lllll}
\hline $\begin{array}{l}\text { Age-group, } \\
\text { years }\end{array}$ & Visor & No visor & $\begin{array}{l}\text { Proportion } \\
\text { with a visor }\end{array}$ & $\begin{array}{l}\text { Odds ratio } \\
(95 \% \mathbf{C l})\end{array}$ \\
\hline$<24$ & 96 & 10 & 0.91 & $5.67(2.52-12.78)$ \\
$24-28$ & 192 & 52 & 0.79 & $2.18(1.23-3.87)$ \\
$29-33$ & 119 & 62 & 0.66 & $1.13(0.64-2.01)$ \\
$>33$ & 44 & 26 & 0.63 & Reference \\
\hline
\end{tabular}

Abbreviation: $\mathrm{Cl}$, confidence interval.

junior leagues, such as the American Hockey League and Canadian Hockey League, which have introduced rules to make visors mandatory. Players in the older age-groups in the NHL entered the league when visors were not as popular or required in the minor leagues, and may have grown accustomed to playing without one. There is significant variation in the use of visors based on country/region of origin, with European players having much higher rates of visor use compared to Canadian players. Previous studies have found that players who do not wear visors are more aggressive players, having more hits, fights, and penalty minutes per season. ${ }^{4,6}$ Among NHL players, it is generally considered respectful as part of the unwritten "code" for aggressive players not to use a visor if they aim to play an aggressive game. ${ }^{7}$ Consequently, Canadian players, who are generally considered to represent a more physical style of play compared to Europeans, may feel pressure to play without a visor. Moreover, European players may have had earlier role models in the game who influenced them to play with a visor.

It is unlikely that NHL players change their choice of wearing a visor from game to game. When we reassessed a random sample of players 1 month after the initial evaluation, there was no change in visor status. A previous study assessed a minimum of 20 games played by each team in the 2003-2004 season, and found that players do not alter their choice of facial protection from game to game. ${ }^{6}$ Since we found that older players are less likely to opt for facial protection, one possible explanation is that younger players begin their careers with a partial visor and choose to take it off as they spend more time in the league. Although we did not address this directly in the study, we believe this is unlikely, given the large increase in visor use overall in the league over the past decade and the consistency with which players wear their visors throughout individual seasons.

This study was limited in that a cross-section of NHL players were examined at one point in time during the season and not all players who had participated in a game during the 2013-2014 season were included. The size of the visors that were used during the season was not assessed. It is possible that some new players in the league choose to wear 
larger visors, which may add additional protection. Although country/region of birth was used to categorize players based on geographic origin, it is possible that some players spent their youth in a place different than where they were born, and this was not evaluated in the current study.

The results of this study have several implications for the future of facial protection in professional hockey. First, it is clear that with time, the use of visors will reach $100 \%$, and this may occur earlier than expected, given the popularity of visors among younger players. The reluctance of the older generation of players appears to be fading out of the league with time. Second, the large difference in visor uptake based on country/ region of origin can allow for targeted interventions for those players. These interventions could involve previously injured players sharing their experiences and sessions from health care professionals. The choice not to wear a visor among many Canadian NHL players has implications beyond professional hockey, as these players serve as role models for amateur players across the country who also have a choice of wearing facial protection in unregulated games.

Overall, with recent legislation in the NHL to mandate the use of visors for rookie players, the use of visors has grown by approximately 5\% from the 2012-2013 to the 2013-2014 season. Younger players are more likely to choose to wear a visor on their own accord. Moreover, there is significant variation in visor use based on country/region of origin, with Canadian players less likely to wear one when compared to their European counterparts. Future studies aiming to elucidate the underlying reasons for this variation can help in growing the use of optional protection to create a safer game.

\section{Disclosure}

The authors report no conflicts of interest studying this work.

\section{References}

1. Brophy M. NHL, NHLPA agree on mandatory visors. 2013. http://www. nhl.com/ice/news.htm?id=672983. Accessed November 17, 2013.

2. Ing E, Ing T, Ing S. The effect of a hockey visor and sports goggles on visual function. Can J Ophthalmol. 2003;37(3):161-167.

3. Stevens ST, Lassonde M, de Beaumont L, Keenan JP. The effect of visors on head and facial injury in National Hockey League players. J Sci Med Sport. 2006;9(3):238-242.

4. Micieli JA, Zurakowski D, Ahmed II. Impact of visors on eye and orbital injuries in the National Hockey League. Can J Ophthalmol. 2014. [In press].

5. National Hockey League, Rookies. [wepage on the Internet]. Available from: http://www.nhl.com/ice/rookies.htm. Accessed February 19, 2014.

6. Stevens ST, Masco JL, Keenan JL. Aggression and visors in the National Hockey League. South Med J. 2008;101(10):979-980.

7. Bernstein R. The Code: The Unwritten Rules of Fighting and Retaliation in the NHL. Chicago: Triumph; 2006.
Open Access Journal of Sports Medicine

\section{Publish your work in this journal}

Open Access Journal of Sports Medicine is an international, peer-reviewed, open access journal publishing original research, reports, reviews and commentaries on all areas of sports medicine. The manuscript management system is completely online and includes a very quick and fair peer-review system.

\section{Dovepress}

Visit http://www.dovepress.com/testimonials.php to read real quotes from published authors. 